\title{
An Evaluation on Land Coordination Use in Nanjing City
}

\author{
Lina Sun \\ College of Economics and Management, Sichuan Agricultural University \\ Ya'an, 625014, China \\ Tel: 86-187-6120-6595Ｅ-mail: sunlinacqr@163.com \\ Xungang Zheng (Corresponding author) \\ College of Economics and Management, Sichuan Agricultural University \\ Ya'an, 625014, China \\ Tel: 86-130-8630-5086 E-mail: zxg9@163.com \\ Hui Chen \\ Tourism and Resources Management College, Zhejiang Normal University \\ JinHua, 321004, China \\ Tel: 86-150-6805-0369 E-mail: ch1985723000@yahoo.com.cn \\ Zhangwei Li \\ College of Economics and Management, Sichuan Agricultural University \\ Ya'an, 625014, China
}

Tel: 86-139-8017-6649 E-mail: mrlizhangwei@hotmail.com

The research is financed by the Ministry of Science and Technology of the People's Republic of China. No. 2006BAJ05A13

\begin{abstract}
Analysis on land use coordination degree is instructive to land intensive use and land sustainable use. The coordination is established to analyze the land use coordination degree of Nanjing from 1999 to 2008; on the basis of this, coordination factors are analyzed by the multiple stepwise regression. The result shows that land use coordination degree in Nanjing has been in a rising trend in the recent ten years, but there is still a distance from the full coordination; we find that the main factors of land coordination use are population growth, economic development and the level of afforesting.
\end{abstract}

Keywords: Nanjing, Degree of coordination, Land use

\section{Introduction}

Land, as the "mother of all things on earth", is the foundation of human existence and development. In all natural resources, land resources will play an important and irreplaceable role in the economic and social development. However, with the development of economy and society, the acceleration of the urbanization process, and the increasing population growth, the contradiction between human and land is exceptionally tense. The experience of the western developed countries tells us: the traditional economic development model which is "at the expense of eco-environment to pursue economic growth "and" treatment after pollution "can't meet the current requirements of the sustainable development . Thus we must seek a way to achieve sustainable development with economy, society, resources and environment all in harmony and make full and rational use of the land.

The coordination evaluation of the urban land use is good to arrange the regional land use reasonably and conduct an optimize way for the allocation of land resources. According to the coordination degree of the land use social system, land use economic system and land use eco-environment system, we can judge the coordinated development of land use, analyze the social and economic development level of land use and the eco-environment situation of land use. In this way, we can provide a scientific guidance to decide a rational land use way.

Nowadays, experts at home and abroad do some related researches on the coordination evaluation of land use and also make many achievements in this area. At abroad, the study of the coordinated development began in 1930s, but they put too much emphasis on social and economic development at that time. In 1990, Norgaard proposed coordinated development theory. He thought that through the feedback loop, the social and ecological systems can achieve common development. Experts abroad pay more attention to the coordinated development between the land and the land for transportation. In order to coordinate land-use related departments, Canada set up Land Use Coordination Department to coordinate the land use related department based on the planning of land use.

In China, the scholars carry out a more comprehensive research on the coordination of land use both in theory and quantitative evaluation. In theory, the representative research is that Liu Feng-zhao, Zhang Bo, Liu Yuan-yuan et al. (2008) hold the same idea that taken the principle of maximizing the city's comprehensive benefits and based on the reasonable economic relations, the coordination of urban land use means that in the 
process of urban land use, various subsystems among the urban land use system should make the urban land achieve its value reasonably and efficiently. In the evaluation of quantity, mainly in the following areas:

(1) Research on the coordination of land use and transportation: Luo Ming, Chen Yan-yan et al. (2008) showed that based on the system theory, combined with the data envelopment analysis and the concept of membership degree on fuzzy mathematics, they constructed the coordination degree model between the traffic and land use, calculated the coordination traffic and land use degree of the eight urban districts in Beijing. As a result, they found that in the past and at present, the traffic and land use complex system had been elementary inconsistent, so they took effective measures to adjust and optimize it.

(2) Research on the coordination of land use and ecological environment: Chen Lei, LI Shu-jie, Zhong Xingguo et al. (2007) showed that through the theoretic analysis of coordinated degree and coordinated development degree, they proposed calculation model based on land use evaluation and eco-environment evaluation, quantitative coordination evaluation degree between land use and eco-environment system to better facilitate land use planning revision work.

(3) Research on the coordination of land use and economic development: Deng Chuxiong (2008) showed that combined with principal component analysis and fuzzy mathematics, they calculated the comprehensive evaluation index of land-use systems and economic development system, they also calculated the two systems' coordination index from the year 1996 to 2005 in Changsha City. Furthermore, in order to analyze the existing problems during the process of economic development and land use, they analyzed the coordination degree of land use and economic development during the 10 years in Changsha, and judged the evolution model of the land use and economic development systems.

(4) Research on the coordination of land use and ecological landscape: Qu Xiaochen (2007) showed that using the landscape ecological theory and methods of eco-landscape pattern, they did some research on dynamic change of eco-landscape pattern in the agricultural and township enterprises in Qu Gou town, Anyang county, Henan province from the year 1996-2005, where the contradiction between human and land was prominent. As the result, they proposed rural land use coordination methods such as landscape dynamics control, hierarchical control, etc.

(5) Research on the land coordination development model : Huang Chengyi, Deng Liangji et al. (2009) showed that combined with mathematical statistics and fuzzy mathematics, took Meishan City for example, they evaluated the coordination of urban land use, concluded that land and other social economic factors were in the basic coordinated state in Meishan City in the year of 2006, but the ecological factor was not coordinated .According to this, they proposed that in the future, we should do more corresponding researches on the sustainable urban land use models.

Based on the entropy and taken the evaluation of land use coordination as a breakthrough, this paper filters evaluation factors through resources ,environment, economics, society, structures the urban land use coordination index system and evaluates the land use coordination in Nanjing to give references to land intensive and sustainable use, furthermore, to better serve the local construction.

\section{General situation of the studying area}

Nan jing, a capital city of Jiangsu province, lies in the plain area of middle and lower reaches of Yangtze River, at the border of Jiangsu and Anhui provinces (Figure1), and has a jurisdiction over 11 regions and 2 counties. It is a synthesized industrial base, an important traffic terminal, a communication center, one of the fourth scientific research and education central cities in eastern China. Moreover, it is a big commercial port which is second to Shanghai in eastern China. By the end of 2008, it has a population of 6244.6 thousand and covers an area of 6582.31 square kilometers, among which the arable land is 242.1 thousand hectares. In the recent ten years, its national economy develops continually and rapidly, in addition, its comprehensive strength upgrades with steady steps.

\section{Data sources and research methods}

\subsection{Data source}

In order to reflect Nanjing's coordinated development of land use, this paper selected Nanjing's social, economic and ecological aspects data of land use from 1999 to 2008, which comes from Statistical Yearbook of Jiangsu Province and Nanjing City, Nanjing economic and social development bulletin.

\section{2 research methods}

\subsubsection{Improved Entropy Method}

To determine the weight of each index is to determine degree of contribution of urban land use affected by index. It is generally acknowledged that improved entropy method is an objective way to determine the weight which can reflect the utility value of information entropy and whose index weight has a higher credibility. This article attempts to use the improved entropy method to determine the weights, as follows:

(1) Because different indicators have different dimension and units, in order to eliminate the dimension and the 
non-commensurability caused by different dimension units, index should be dimensionless. The standard formula is:

$x_{i j}^{\prime}=\frac{x_{i j}-\bar{x}_{j}}{s_{j}}$

In the equation, $x_{i j}^{\prime}$ is the dimensionless index; $\bar{x}_{j}$ is the mean value of the item $j ; s_{j}$ is the Standard deviation of the item $j$.

(2) Translate the coordinate to eliminate negative value. After the translate, $x_{i j}^{\prime}$ become $x_{i j}^{\prime \prime}$, and $x_{i j}^{\prime \prime}=A+x_{i j}^{\prime}, A$ is the extent of translating.

(3) Calculate specific gravity of $x_{i j}^{\prime \prime}$ in $R_{i j}$, and $R_{i j}=x_{i j}^{\prime \prime} / \sum_{i=1}^{m} x_{i j}$.

(4) Calculate entropic value $e_{j}$ of the item $j$, and

$$
e_{j}=-\frac{1}{\ln m} \sum_{i=1}^{m} R_{i j} \cdot \ln R i j \text {. }
$$

(5) Calculate the difference coefficient $g_{j}$ of the item $j$ index, following the equation: $g_{j}=1-e_{j}$, the bigger the $g_{j}$ is, the more important the $x_{j}$ index is in the comprehensive evaluation.

(6) Calculate the the weigh $w_{j}$ of index $x_{j}$, following the equation

$$
w_{j}=\frac{g_{j}}{\sum_{j=1}^{n} g_{j}} .
$$

\subsubsection{Coordination function}

Calculate the coordination index $v_{i}$ of socio-economic and ecological development, using Multi-objective comprehensive evaluation method, after determined the weight of evaluating index. Follow the equation:

$v_{i}=\sum w_{j} \cdot x_{i j}$,

and $\mathrm{w}_{\mathrm{j}}$ is the weight of index, $\quad \mathrm{x}_{\mathrm{ij}}$ is the value that initial data has been extreme difference standardized.

According to the content of coordinated development, coordinated development should be the equilibrium of Economic development index, social peogress index, Ecological support index.

The more coordinate is among the three indexes, the closer the evaluation indexes are, and vice versa. Define the coordinated degree of the sample $\mathrm{i}$ :

$c_{i}=1-s_{i} / f_{i}$,

In the equation, $s_{i}$ is the Coordination coefficient of social conditions of sample $\mathrm{i}, f_{i}$ is the mean value of the three coefficient of sample $i$. Coordinated degree $c_{i}$ means coordination of urban land use system, the value of $c_{i}$ is between 0 and 1 , the bigger the value of $c_{i}$ is, the better the Coordination of land use system is and the higher the Comprehensive benefits are.

\subsubsection{Multiple linear Stepwise regression}

Multiple linear regression model is usually used to explain the change of land use. We can build a mathematical model through analyzing the multivariate factors that can cause the change of land use to definitely distinguish the reason of the change of land use. The fundamental principle of multiple linear regression analysis is: suppose that there is a liner relationship between random variable $Y$ and $X_{1}, X_{2}, \ldots, X_{m}$, then the mathematical model is $\mathrm{Y}=\mathrm{A}=\mathrm{a}_{1} \mathrm{X}_{1}+\mathrm{a}_{2} \mathrm{X}_{2}+\ldots+\mathrm{a}_{\mathrm{m}} \mathrm{X}_{\mathrm{m}}$. To solve the undetermined coefficient $\mathrm{a}_{1}, \mathrm{a}_{2}, \ldots, \mathrm{a}_{\mathrm{m}}$, using $\mathrm{n}$ troop of observed value $\left(\mathrm{X}_{1 \mathrm{i}}, \mathrm{X}_{2 \mathrm{i}}, \ldots, \mathrm{X}_{\mathrm{mi}}, \mathrm{Y}_{\mathrm{i}}\right)$ according to the least squares method. 


\section{Result analysis}

\subsection{Coordinated degree analysis}

Building the weight through entropy method and using Coordinated degree function to calculate the Nanjing's Coordinated degree of land use between 1999 to 2008, just as table 2 shows. In order to shows the trend of 10 year's change, adopting trend chart of changing to show the change of coordinated degree, just as figure 1 shows.

From table 1, we can see that Nanjing's coordinated degree of land use is overall in rising trend and there is a good development tendency among the land use resources, economic and society's coordination situation. According to the standard of Coordinated degree level (table 3), we can approximately divide the Nanjing's last 10 years' coordinated situation of land use into 3 periods:

First period: 1999-2002, in these years, the land use is under the state of not too coordinated, which suggests that in the process of land use, there is not too coordinated among social, economic and environmental system of land use, and there is a bad effect on the sustainable use of land use. In this period, the economic development index was much higher than that of social peogress index, ecological support index. We can give an explanation that with the development of economy and society, human pay excessive attention to the economic, and thus the economic develop rapidly, but neglect endurance of society and environment.

Second period: 2003-2006, in this period, the land use is under the state of highly coordinated, resources, social and economic systems are completely coordinated, the system of land use is fully developed towards orderly direction. We can conclude that according to the first period human has already realized the crisis of it and taken much steps to protect the land, thus to achieve land sustainment use.

Third period: 2007-2008, in this period, the land use is under the state of better coordinated, but there is still a gap between the highly coordinated situation, and a large potential to explore. In the future, we must pay much attention to the coordination between economic, society and environment.

\subsection{Analyzing the factors of land coordinated use}

In order to better show the influence degree of each evaluating indicator, we set each factor as the independent variable, and area of land as the dependent variable, using Eviews3.1 to do the multiple linear stepwise regression analysis, and then obtained the multiple linear regression model between Nanjing's areas of land changing and factors:

$$
\begin{gathered}
y=1912.259-3.2409 x_{1}+0.056515 x_{3}+10.82253 x_{7} \\
\quad(8.1858) \quad(-6.3809) \quad(5.2633)
\end{gathered}
$$

Related coefficient $R_{2}=0.946, F=53.807$ has passed significance test of $95 \%$ confidence coefficient, that is to say the model's degree of fitting is relatively good. Regression coefficient means the sensibility that the area of land changing affected on the factors, and then we can come to a conclude that three factors--population, GDP and green area per person are relatively sensitive, and the factor of green area per person represents extremely prominent. It represents that the level of afforestation plays an important in the courses of land use.

\section{Conclusion and Discussion}

By constructing coordination degree function and establishing relevant index system, this paper calculates the land use coordination degree in Nanjing from the year 1999 to 2008. The results show that as a whole, the land use coordination degree in Nanjing has an upward trend over the past ten years, the coordination state between land use social system, land use economic system and land use eco-environment system have a good momentum, however, compared with the state of high coordination degree, there is still a gap.

The coordination factors are analyzed by the multiple stepwise regression, the results show that the growth of population, the development of economy and the level of afforesting are the main factors of land coordination use.

Through the analysis of the factors, the author believes that the key points to improve the land coordination use in Nanjing are as follows:

(1) Strengthening the afforestation in the built-up area. At the end of 2008, the area of afforestation per person in built-up area in Nanjing was $13.2 \mathrm{~m} 2$, which is lower than the standard made by United Nations, where the area of afforestation per person was $50-60 \mathrm{~m} 2$.what's more, it is much lower than the developed countries. In the course of the future development, we should optimize the structure of urban land use, increase the proportion of greenbelt during the construction of the city and pay much attention to the importance of afforestation in protecting the environment and beautifying the city.

(2) Handling the relationship between the land use and economic development correctly and driving the economic growth reasonably. As a city where the economy grows rapidly, the economic factor has a dramatic effect on the change of land use coordination and the economic development should not be carried at the cost of the land or even the cultivated land. We should properly threat the relationship between them and achieve a 
sustainable land use authentically.

(3) Controlling the population growth strictly and optimizing the population structure. Population is a major factor in affecting the land use coordination. Population growth makes the conflicts between population and land more severe. We should firmly follow the family planning policy, control the speed of population growth and the scale of population strictly, thus to decrease the land pressure, especially the cultivated land.

(4) Creating the environmental and friendly land use model. Aimed at the specific geographical units, the so-called environmental and friendly land use model is to protect and improve ecological environment, and to use land in a intensive and sustainable way. The environmental and friendly land use model must ensure the reasonable requirement of land for the current social and economic development, and it's also a fundamental way to keep sustainable supply of the needed land ,to protect resources and improve the ecological environment effectively. In the future development, we should focus on the development of high-tech industries and large-scale basic industries in the city centre, while striving to develop labor-intensive enterprises in the urban area, thus to promote the industrial agglomeration, develop the circular economy, use the land intensively and improve the economic efficiency of land.

\section{References}

CHEN Xing-lei, LI Shu-jie, GUO Zhong-xing. (2009). Analysis on the harmonious degree between land use and ecological environment in Yanbian Korean Autonomous Precfecture,Jilin Province. China Land Science, 23(7):66-69.

DENG Chu-xiong, XIE Bing-geng, WU Yong-xing, ZHANG Hai-yan, et al. (2008). Quantitative evaluation study on coordinating development of land use and economy in Changsha city. Economic geography, 28(4):677-681.

Executive summary and report of the WisDOT Land Use workgroup.Transportation and land use coordination.2002:1-64.

HUANG Cheng-yi, DENG Liang-ji, ZENG Wei-zong, LI-Hong. (2009). Study on coordinative evaluation and utilization model of sustainable use of urban land-taking Meishan City as an example. Soft science,23(2):101-105.

LIU Feng-chao, ZHANG Bo, LIU Yuan-yuan, SUN Yu-tao. (2008). Coordinating degree assessment on urban land use system:a case of Dalian.China Land Science,22(12):25-30.

LUO Ming, CHEN Yan-yan, LIU Xiao-ming. (2008). Study on coordination degree model between urban transport and land use.Journal of Wuhan University of Technology(Transportation Science \& Engineering),32(4):585-588.

LUO Yong-ge et al. (2008). Evaluation of urban land intensive use based on improved entropy method. Modern business trade industry, 7:105-106.

Norgaard R R. (1990). Economic Indivators of Resource Scarity: a Critical Essay.NewYork.Journal of Environment Economics and Management.

PAN Ya-ru, SONG Hai-peng, TAN Jing. (2009). Agricultural land use intensity evalution and regional disparity analysiss in Sichuan Province. Journal of Sichuan Agricultural University, 27(3):387.

QU Chen-xiao. (2007). Study on land scape coordination during new rural development. Resources \& Industries, 9(4):60-63.

QU Fu-tian. (2001). Development of society and land sustainable use.Beijing: People's Publishing House Wiseonisn Department of transportation.Land use coordition \&Policy development.2009.

WANG Zeng-yan et al. (2008). Analysis on the dynamic changes of cultivated land resources in Guangxi and its driving force. Journal of Anhui Agricultural Sciences, 36(25):11040. 
Table 1. Index system of land coordination use in nanjing

\begin{tabular}{|c|c|c|c|}
\hline The layer of a goal & $\begin{array}{l}\text { The layer of } \\
\text { the standard }\end{array}$ & The layer of the index & Weight number \\
\hline \multirow{18}{*}{$\begin{array}{l}\text { Land coordinative } \\
\text { evaluation }\end{array}$} & \multirow{8}{*}{ resource } & Land per person & 0.0454 \\
\hline & & Cultivated land per person & 0.0929 \\
\hline & & The standard rate of waste water & 0.0193 \\
\hline & & $\begin{array}{c}\text { Decrement of cultivated land per } \\
\text { year }\end{array}$ & 0.1624 \\
\hline & & Living area per person & 0.0607 \\
\hline & & Greenbelt per person & 0.0490 \\
\hline & & GDP per person & 0.0715 \\
\hline & & Land productivity & 0.0716 \\
\hline & \multirow[t]{6}{*}{ economy } & Output of foods each unit & 0.0135 \\
\hline & & The proportion of agriculture & 0.0562 \\
\hline & & The proportion of tertiary-industry & 0.0237 \\
\hline & & $\begin{array}{l}\text { The investmentof social permanent } \\
\text { assets per person }\end{array}$ & 0.0659 \\
\hline & & Population density & 0.0461 \\
\hline & & Urbanization level & 0.0267 \\
\hline & \multirow[t]{4}{*}{ society } & $\begin{array}{l}\text { The proportion of the } \\
\text { undergraduates }\end{array}$ & 0.0341 \\
\hline & & $\begin{array}{l}\text { Urban per capita disposable } \\
\text { income }\end{array}$ & 0.0757 \\
\hline & & collection of books in library & 0.0463 \\
\hline & & engel's coefficient & 0.0391 \\
\hline
\end{tabular}

Table 2. Land use coordination degree in Nanjing from1999 to 2008

\begin{tabular}{ccccccccccc}
\hline Year & 1999 & 2000 & 2001 & 2002 & 2003 & 2004 & 2005 & 2006 & 2007 & 2008 \\
Degree & 0.4690 & 0.4460 & 0.4818 & 0.2931 & 0.7088 & 0.9494 & 0.8002 & 0.8325 & 0.7446 & 0.7775 \\
\hline
\end{tabular}

Table 3. Appraisal table of land-use system coordination degree

\begin{tabular}{llll}
\hline \multicolumn{1}{c}{ The range of $C$} & \multicolumn{1}{c}{ The grade of $C$} & \multicolumn{1}{c}{ The range of $C$} & \multicolumn{1}{c}{ The grade of $C$} \\
$0.8 \leq \mathrm{C}$ & Coordinated in a high degree & $0.4 \leq \mathrm{C}<0.5$ & Not too coordinate \\
$0.6 \leq \mathrm{C}<0.8$ & Coordinated Relatively & $0.2 \leq \mathrm{C}<0.4$ & Uncoordinate \\
$0.5 \leq \mathrm{C}<0.6$ & Coordinated elementary & $\mathrm{C}<0.2$ & Rather uncoordinate \\
\hline
\end{tabular}




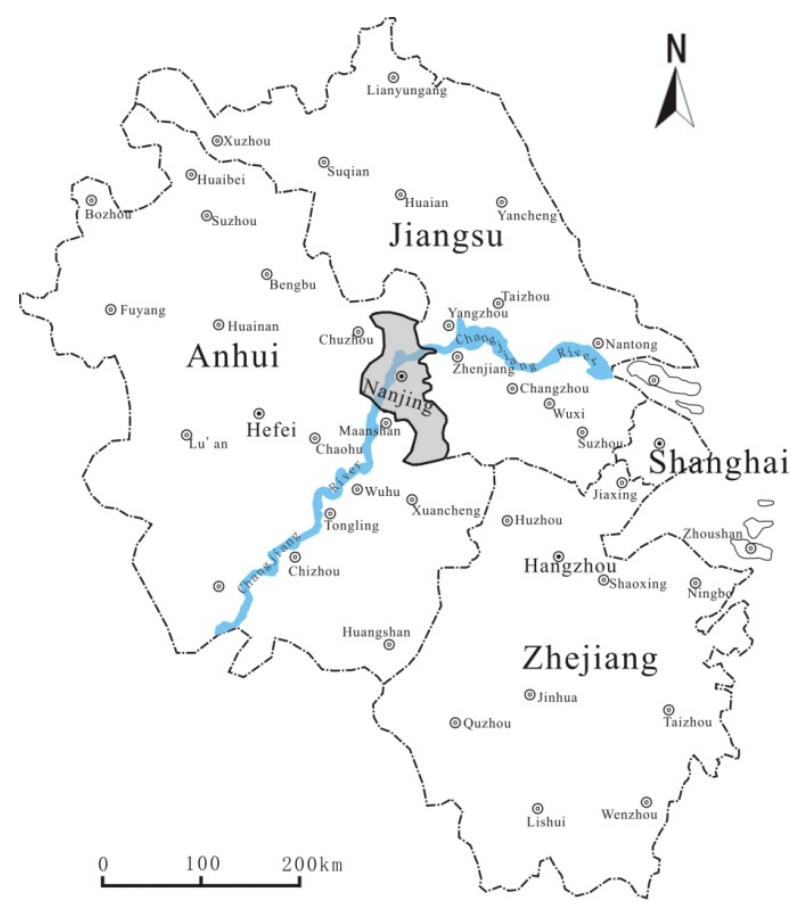

Figure 1. The Map of the Cities Encompassing the Yangtze River Delta Note: the city of Nanjing is bolded in gray

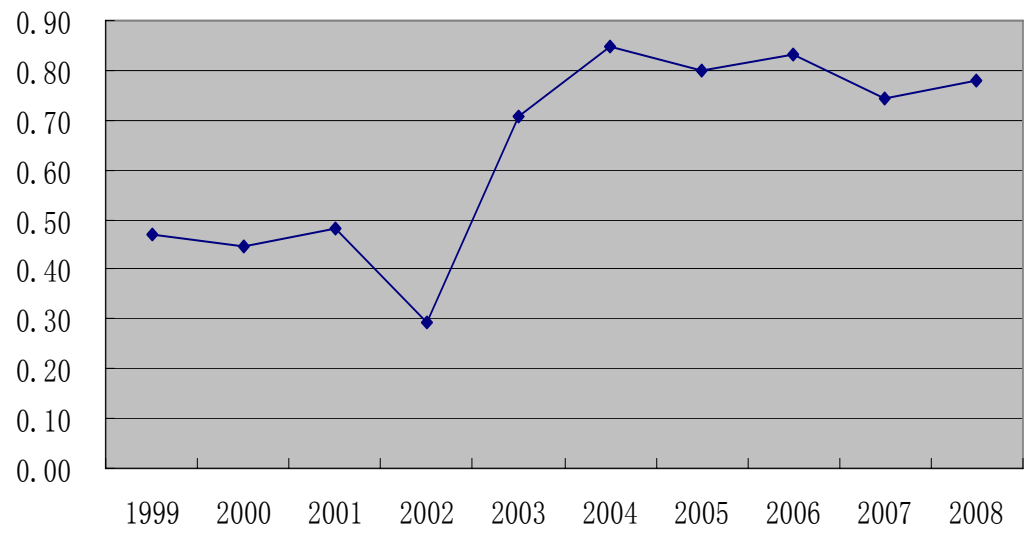

Figure 2. The Trend of Land use coordination degree in Nanjing from1999 to 2008. 